\section{Operationalizing Integrative Sustainability in National Policy Frameworks}

\author{
by Krassimira Paskaleva, Forschungs- \\ zentrum Karlsruhe
}

This contribution presents a synopsis of the operationalization of the integrative concept of sustainability in four national plans based on an evaluation scheme which identifies four main categories of national policy for sustainable development: (1) Conceptual approach and theoretical framework (2) Problem fields (3) Goals and targets and (4) Activity fields. The primary objective is to provide a comparative analysis ${ }^{1}$ of these categories to demonstrate how the concept of integrated sustainability is applied in different national frameworks related to structure of governance, policy making, political economy, and culture.

\section{Introduction}

Over the past decade, stimulated by the 1987 Brundtland Report and the 1992 Rio Conference, sustainable development has become an internationally accepted concept for environmental and development policy. The concept has been central to a series of initiatives worldwide, ranging from the draft EU Treaty of Amsterdam to UN's Local Agenda 21. The definition and conceptualisation of sustainable development has evolved since the late 1980s. Despite various interpretations of the concept, however, there is a common notion that sustainability incorporates environmental as well as economic, social, and institutional dimensions. Equally important are issues of natural limits, justice, human rights, equity, human progress and participation (Paskaleva 2000). But articulating these elements into tangible operational policy is an important challenge.

\section{The Concept of Sustainability in National Policy Frameworks}

Despite broad theorizations, the concept of sustainability remains underdeveloped and poorly operationalized in national policymaking. Some emerging theories assert that global change, ecology and political economy are devolving power and authority away from the nation-state and towards a greater reliance on supranational, regional, and local levels of governance of sustainable development (Hempel 1996). However, others argue that nations remain "the major units of community capable of carrying out any policies for the "Common good" (For example, see Daly 1998). Existing works, however, focus primarily on the planning process of developing national programs for sustainability (Carly and Christie 1992; Jänicke et al. 1996). Comprehensive studies of the operationalization of the integrated approach of sustainable development in national contexts to assist the "delivery" of sustainability in life are still missing. At the same time, many international and national efforts stress the role of national strategies to implement the UN's Agenda 21 (UN/CSD 1999). Nonetheless, few, if any, fully integrated national programs for sustainable development have been implemented. The majority of existing plans, while recognizing the multidimensionality of sustainability, focus on environmental aspects (Examples include "New Zealand Environment 2010 Strategy", cf. New Zealand Ministry for the Environment 1995, and the "Russian Federation Environmental Action Plan", cf. Russian Federation Ministry of Natural Resources 1999). Other countries have elaborated National Action Plans in line with Agenda 21, which generally provide no justification of the selected methodology and the criteria used to elaborate the goals, policies and the measures towards sustainability. They also lack a comprehensive approach to sustainability and bridges to promote synergies with other sectoral plans to pursue a common sustainable path (See "National Action Plan for Agenda 21 of Republic of Korea", cf. Republic of Korea 1996; and "Japan's National Agenda 21 Action Plan", cf. Environment Agency of the Government of Japan 1993). Many decision-makers still perceive sustainable development to be an enhanced form of environmental protection instead of a broad concept, which integrates environmental, social and economic dimensions (Bernstein 1998). 
A national plan for sustainable development (NPSD) involves ongoing, transparent, and cost-effective policy, institutional and investment actions to improve environmental quality and social and economic development over the long term. This is a new approach in national policy-making. To date there is no single mode yet to follow and the scope and definition of NPSD is just evolving. It has become apparent however, that the process of its development and implementation is closely linked to the overall process of defining sustainability on various levels and its introduction into existing traditional policies. It has also been recognized that national plans for sustainability can provide comprehensive conceptualization of the existing problems and draw the guidelines for operationalizing the concept on multiple scales. They can also define strategic directions, design standards and instruments, forge consensus and use multiple channels to disseminate, monitor, update and evaluate policies. Analysing and comparing existing practices in national planning for sustainability will help us develop an integrated framework of sustainable development to serve various national contexts.

\section{Methodological Approach}

Sustainable development refers to system-wide and long-term processes and conditions. Following early notions that man depends on nature and that nature is nowadays increasingly dependent on mankind, the new perspectives of sustainable development are multi-dimensional, as clearly demonstrated by Pezzy (1998), who discusses physical, ecological, economic, physiological, sociological, and especially, historical elements of sustainable development. Majority of scientists also agree that a total-system views may serve a good practical purpose (van den Bergh and van der Straiten (Eds.) 1992), i.e. an effective implementation of the sustainability paradigm is only possible if all dimensions are consistently viewed in interdependence, a notion also known as an "integrated approach" to sustainability.

Based on this assumption, an evaluation scheme is developed which allows a systematic analysis of the elements of sustainability on the national level and demonstrates the relationship between theory, goals, problem fields, activity fields and reduction targets necessary to achieve sustainable development. It also involves an assessment of the conceptual frameworks of the selected plans in terms of their implementation and identifies its contradictions, deficiencies, and inconsistencies (Joerissen and Paskaleva 1998). Specifically, the framework of analysis includes

(1) Conceptual approach and theoretical framework, examining the primary ethical assumption of the study emphasizing on key issues such as

- $\quad$ vision of sustainability

- dimensions of sustainable development and their relationships

- intra-/ or intergenerational equity),

- development versus growth, and

- criteria for defining sustainability

(2) Problem-fields, exploring

- the nature of existing problems

- relevancy of criterion selection

- causal links

- $\quad$ spatial framework, and

- link between problem-fields and actionfields

(3) Goals and targets, analysing the theoretical and methodological basis for defining the goals in respect to

- clear definition

- relation to current trends and emerging problems in environment, economy, and society

- $\quad$ limiting existing problems or achieving a desired level of sustainability in the action fields

- $\quad$ prevention or reduction of risks

- qualitative or quantitative characteristics

(4) Activity fields designed to realize the goals in terms of

- types of social activities

- justification of selection, and

- methodological difficulties and inconsistencies.

Finally the link to implementation is addressed to discuss the level of operationalizing the concept of sustainability to serve practical efforts. 


\section{Assessment of Plans}

The plans examined here are the "Finnish Government Program for Sustainable Development" (Finnish Ministry of the Environment 1998), the United States Program "Sustainable America: A New Consensus for Prosperity, Opportunity, and a Healthy Environment" (US PCSD 1996), the "Austrian National Environmental Plan" (NUP) (Austrian Ministry for Environment, Youth and Family Affairs 1995), and the United Kingdom's Program "Sustainable Development: The UK Strategy" (UK Department of the Environment 1994). The principal consideration for selecting those plans is the employment of the integrated approach of sustainability to national policy development. Additional factors such as availability, accessibility, and language compatibility were also important.

\section{Conceptual approach and theoretical frame- work}

The Brundtland definition of sustainability forms the heart of each country's specific approach to national sustainability: Sustainable development is seen as a process of balance between fundamental socio-political goals and long-term preservation of the environment at the global, regional and local levels, aimed at providing every opportunity to present and future generations to lead a good life. Despite this common notion, interpretations of the vision vary: Sustainability is defined either as a "human responsibility", "equal opportunities", "preserving the quality of life and nature", "equal access to resources", or as "reconciliation of economic goals with environmental quality". The Austrian program goes a step further and considers sustainability as a strategy to counter deterioration in the social sectors. However, although the vision is usually well articulated and directed to the country's specific conditions and challenges, guidelines for its operationalization at different levels are generally lacking.

As the political and institutional framework of the examined programs differ, so do the conceptual approaches to defining the problems, and the types of models chosen for analysis of these problems, the latter varying from no system approach (US) to system analysis of the environment (Austria and UK), and to a system approach to all three dimensions of sustainability (Finland and Austria). There are also differences in the adopted models of structural transformation, the leading principles of sustainability, the visions of equity and the employed concepts of growth and development. While the Finnish, UK, and the Austrian cases present a combined anthropocentric and nature-balanced model of sustainable development, the US's anthropocentriccentred framework stresses economic prosperity, welfare and human satisfaction in setting the goals of sustainability.

In Austria and Finland, both with a strong legacy in nature preservation, the accent is on the environmental management principles (nature preservation, wise use of resources, considerations of nature's carrying capacity, equitable costs and, precautionary principle, burden sharing, prevention over contamination and remediation, impact assessment, etc). Furthermore, in the European programs, the generic principles also employ both sectoral and dimensional specificity, which has allowed the operationalization of the concept of sustainability from its multiple aspects.

All programs consider both intergenerational and intra-generational equity, despite the differences in the level and scale of their specification. In the earliest program of UK, however, the equity principles are not explicitly articulated though considerations of their elements appear in the context of the main policy topics - environmental preservation, population and economic development, leisure, and public involvement. Similarly, the US program, despite the various interpretations of the concept (viewed primarily as intragenerational) such as "meeting today's needs without compromising future needs", "equality of opportunity", "reducing disparities in risks and access to benefits" or "equal distribution of environmental burdens" presents a, generally, confined and vague vision of equity failing to account for sectoral interrelations, social and economic inequalities, not establishing the link to problems of resource use, over-consumption and poverty, or existing societal and regional disparities in the country. On the other hand, the two more recent programs of Austria and 
Finland, place a significant emphasis on the need to view the two dimensions of equity as equally important. Intergenerational equity is typically defined in more general terms (as "guaranteed opportunities of future generations to safe environment", "access to use of vital resources" or "optimum biological diversity"), while intra-generational equity is viewed as complex and is considered from the key dimensions of sustainability:

- environmental ("equal burden and benefits" and "sharing and securing a better environment")

- social (viewed in context of "opportunities", "rights", "responsibilities", "balanced distribution of welfare", "elimination of poverty", "security of employment", "participation in decision-making", and "preservation of cultural diversity"), and

- economic equity ("basic welfare", "improved standard of living for all", and "promotion of quality employment").

Moreover, the role of culture, ethics, and institutions is specifically empathized in the above works.

The multi-dimensional view of equity redefines the concept of economic growth to refer not just to the economy, but to employ ecological and social considerations as well, i.e. societies must pursue integrated development as an alternative to economic growth per $s e$. This requires fixing current market malfunctions to consider both, environmental impacts and values and a broad-based social prosperity. In this line of thought, the Austrian National Environmental Plan, for instance, affirms that the "current concept of growth is inappropriate". Moreover, viewing economic growth from the perspectives of the mass flows through nature, society and economy, has allowed determining that "current development trends are not acceptable any more". Therefore, "growth needs to be coupled with the quality of life and the environment". To achieve this, economic growth "needs to be redirected to resource management, resource multiple use, rise of immaterial quality of life and quality of products". The Finnish program, though far less ultimately, similarly asserts, "growth is possible but not ultimate". This concept, how- ever, is considerably different than the US approach which centres on economic and social growth implying the superiority of the market forces and defining the market as the "most effective machine for shaping sustainable development". Less ultimately, the UK's strategy too implies the consistency between growth and sustainability, which should be, however, "wisely guided".

The prevailing view of growth and development is reflected in the preferred approach to structural transformation. While the UK and US programs prioritise resource efficiency (reducing material and energy input for a unit of product or service output), the Finnish and Austrian strategy also involves the principles of sufficiency (restricting consumption of goods and services by changing lifestyles) and consistency (increasing consistency of natural with human flows of materials). It is emphasized, however, that achieving consistency is most feasible at the local level where policy efforts should be primarily focused.

\section{Problem fields}

Overall, multiple scales are identified on which problems of sustainability must be tackled. Even so, the main focus is primarily on global and national levels. Nevertheless, though definitions of the world's most critical ecological problems are almost identical in all plans (such as climate change, forest depletion, and reduced biological diversity), the extent of focusing on global economic and social issues varies. The US approach centres around the "advantageous" sides of current development (advance of democracy, intensive flow of capital, trade, information, investments, and people across borders, and a growing demand of products and services). The European countries underpin national policies for sustainability more from the perspectives of the "ills" of post-modern trends of economic growth - increased production of goods and services, energy and resource consumption, economic and regional inequality, unemployment, poverty, population growth, widening gap between rich and poor, and finally, the unprecedented level of growth of the industrialized countries. The "harms" of modern development form the base to elaborate on de- 
sired changes in a large range of socioeconomic issues such as social prosperity, better education and health care, gender equality, welfare, regional equalities, social rights and large-scale advance of democracy.

The above "global" areas of concern form the base line for formulating the domestic problems of sustainability in all four plans. The different level of detailization and specificity reflects, however, the general conceptual framework of each plan. For example, in the US program, the national problems of sustainability are primarily linked to the issues of technology use (boom in communication and technology innovation) and trust and confidence (erosion of central power and confidence in large institutions). The European programs instead focus on either the domestic environmental problems and levels of resource consumption (UK), or provide a comprehensive list of those problems from the perspectives of each aspect of sustainability (Finland), or, even more, analyse them in the context of the key dimension (Austria). This has provided the opportunity to more explicitly formulate each country's goals and the action fields necessary to realize those goals, both from the perspectives of the specific time frame and the national space. The approach has also justified the call for a shake-up in personal and public awareness, reduction of consumption, and changes in lifestyle patterns of their societies and the modern world, as a whole.

\section{Goals and targets}

Depending on the form and content of the programs (political agendas versus comprehensive plans for action), the goals of the plans substantially differ in types, scale, and level of quantification. The objectives of nation-wide sustainable development are either generally stated or only qualitatively described (US and Finland), or specifications are given for quantitative reductions of resource use and pollution emissions (UK and Austria). Furthermore, while the Finnish goals are selected systematically (using the all system approach), the US objectives are more fragmentally chosen, also lacking a clear criterion for selection. The Austrian plan is most comprehensive, between all, formulating both universal qualitative and quantitative goals and multiple sector-specific qualitative and quantitative targets towards sustainability. In terms of scales, while the US program selects goals for 10 specific fields of problems, its European counterparts essentially set goals of sustainable development relevant to sustainability's multiple aspects reflecting both current trends and the emerging problems. This has allowed them to tackle generally understudied areas such as the trade-offs between the different goals or to set objectives aimed at the increase of nature's carrying capacity and to call for an economic realignment (closed production pathways, energy saving measures, quality products), reduction of resource utilization, and the consideration of the limits of pollution. On the spatial level, all four programs assert the importance of promoting a national framework of sustainability to guide nationwide policies. It is implied that this must be achieved by work on regional and local levels where issues of environmental preservation, as well as social and cultural problems, can be best tackled.

\section{Activity fields}

The national goals towards sustainability have defined the main activity fields of each country. However, while in the political programs the areas for action emerge as "main activity areas" (US), or similarly, as "lines of action" (Finland), in the comprehensive plans the priority actions are organized by sectors (Austria) or are viewed in the context of each key perspective of sustainability (UK). To provide a link to implementation, the US and UK programs make a step further recommending actions to all key players from the business community, government, academic institutions, and the public.

Although the action strategies proposed by each plan generally consider all aspects of sustainability as equally important, they also set certain priorities. Prevailing criteria include the impact on human health, economic prosperity, equity, and nature conservation (US). Other criteria include quality of life, nature's carrying capacity, nature conservation, or curbing the potential of irreversible environmental effects (Finland and Austria). A third type of criteria includes strong social dimen- 
sions such as the "deteriorating conditions in the social sector and people's welfare" (Austria and Finland). However, even though prioritisation has often been carried out, in all cases the criteria used were not explicitly stated. In some plans, criteria appear as general goals of sustainability providing no explanation of how they were applied to determine policies. Overall, it is difficult to distinguish between criteria, problems, and the goals of the plans.

\section{Concluding Remarks}

In countries that have a greater centralization of government, institutional framework and environmental management like Austria and the UK, the national strategy for sustainable development takes the form of a detailed national plan or a government program. In Austria in particular, where environmental protection has played a great role in shaping national environmental policies, this is a comprehensive environmental management plan, which, besides for the ecology, accounts for all other aspects of sustainable development as viewed in the current paper. In the UK, on another side, which has had a long trust in environmental economics, reconciliation of basic economic goals with environmental quality is in the heart of its national program towards sustainability. In contrast, in Finland and the USA, in particular, where central policies are largely defused, the national program serves the purpose of providing broad political visions and wisdom of the current governments towards shifting the whole society to a more sustainable future, however, with a limited concreteness of the desired targets and the necessary actions. Development of the plans has generally served a variety of other purposes too, such as endorsing new politics, setting directions and goals, promoting sustainability principles and values, elaborating new policy principles, advocating changes in behavioural patterns and structures, and redesigning institutions and institutional approaches.

Conceptually, all four plans share a common ethical assumption emphasizing on the integrated approach to achieving national sustainability. Economic, political and cultural factors have been driving in defining key national priorities, goals and policy actions. There is also a wide recognition that the solutions to the problems of today are to view and deal with environmental and societal changes in a holistic manner. However, in plans seeking both qualitative and quantitative implementation, it appears that sustainability has been essentially operationalized in its environmental dimension. In the "agenda-setting" programs, it has been apparently easier to articulate integrated and holistic visions at the expense of nonmandatory implementation targets.

Generally, it has been difficult to operationalize the concept interactively in practical policy terms. Neither of the examined programs provides a systemic policy model involving all dimensions of sustainability. But, as it has also been argued by Lélé (1991) the concept needs to be operational, therefore the broadness needs to give way to more specificity. Clearly, whatever an activity is sustainable or not depends on its motivation or inputs (links to society and ecological sources) and outputs (links to society and ecological sinks). Operationalizing sustainability using these links leads us to a hierarchical view of the world in which problems are approached from their various layers integratively and the solutions may present themselves by looking at the various links between these layers. Quantifying those layers, as in the Austrian and the UK plans, provides a better possibility for "delivering" the concept of sustainability. Moreover, approaching sustainability from its multiple aspects allows the application of the system approach to the analysis of nature, economy and society linked together. The lack of such approach could likely lead to the prioritization of certain dimensions of sustainability where actions may fail to account for impacts in other critical areas of development.

Thus, to summarize, it can be concluded that national policy-making for sustainable development is about defining a vision that is compelling to the society and articulates clear goals which can bring all people together to carry it into the future. Operationalizing those goals into concrete policies, actions, and measures, in space and time, is the next step towards the success. 


\section{Footnote}

1) For detailed analysis of the country plans and policy implications of planning for sustainability see Paskaleva 2000.

\section{References}

Austrian Ministry for Environment, Youth and Family Affairs, 1995: Austrian National Environmental Plan. Wien

www.bmu.gv.at/admin_umwelt/admin_u_nup/frmse t_nup_a.htm

Bernstein, J., 1998: Report of the Second Western European Roundtable of National Councils for Sustainable Development. Brussels http://ncsdnetwork.org/europe/reports/brussels/.

Carly, M. and I. Christie, 1992: Managing Sustainability. Earth Scan Publications, Ltd.

Daly, H., 1998: Reconciling Internal and External Polices for Sustainable Development. In: Sustainability and Global Environmental Policy: New Perspective. Edward Elgar, Cheltenham, UK

Environment Agency of the Government of Japan, 1993: Japan's National Agenda 21 Action Plan.

http://www.eic.or.jp/eanet/index-e.html.

Finish Ministry of the Environment, 1998: Finish Government Program for Sustainable Development. Helsinki

Hempel, L., 1996: Environmental Governance. Island Press, Washington, D.C., California

Jänicke M. et al, 1996: Studie über die Erstellung eines nationalen Umweltplans. Gutachten erstellt für die Enquete-Kommission "Schutz des Menschen und der Umwelt" des 13. Deutschen Bundestages. Berlin

Jörissen, J. and K. Paskaleva, 1998: The Integrated Concept of Sustainability: Study Outline. Work document under the HGF Project "Global zukunftsfähige Entwicklung: Perspektiven für Deutschland", ITAS, Research Centre Karlsruhe, Germany

Lélé, Sh., 1991: Sustainable development: a critical review. World Development 19(6)

New Zealand Ministry for the Environment, 1995: The New Zealand Environment 2010 Strategy http://www.mfe.govt.nz/management/index.htm. Paskaleva, K., 1999: Operationalizing Integrative Sustainability in National Policy Frameworks: Theoretical Considerations and Policy Implications. In: Jörissen, J. et al: Synopse zur Umsetzung des Leitbildes der Nachhaltigkeit in konzeptionellen Studien und nationalen Plänen, Forschungszentrum Karlsruhe, ITAS, (Abschlussberichte HGF-Projekt, Band 1) Pezzy, A., 1998: Sustainability: An Interdisciplinary Guide. Environmental Values 1, White Horse Press Russian Federation Ministry of Natural Resources, 1999: Russian Federation Environmental Action Plan. Unpublished draft
Republic of Korea, 1996: National Action Plan for Agenda 21. Ministry of Environment, Seoul UK Department of the Environment, 1994: Sustainable Development: The UK Strategy. London UN/CSD Seventh Session, 1999: Assessment of Progress in the Implementation of Agenda 21 at the National level: Table of Key Coordination Mechanisms and Actions. Background paper No. 12

http://www.un.org/esa/sustdev/natlinfo/.

US PCSD, 1996: Sustainable Development: A New Consensus for Prosperity, Opportunity, and a Healthy Environment for the Future. U.S. Government Printing Office

van den Bergh, $G$ and J. van der Straaten (Eds.), 1992: Towards Sustainable Development. Island Press

\section{Contact}

Krassimira Paskaleva

Forschungszentrum Karlsruhe $\mathrm{GmbH}$

Institut für Technikfolgenabschätzung

und Systemanalyse (ITAS)

Postfach 3640, D-76021 Karlsruhe

Tel.: + 49 (0) 7247 - 822501

Fax: + 49 (0) 7247 - 824806

E-Mail: Paskaleva@itas.fzk.de

\section{Nachhaltigkeit und Praxis: Ernüchternd, aber nicht entmutigend - ein Resümee}

\section{von Wolfgang Fischer, Forschungszentrum Jülich}

„Global denken und lokal handeln“. So lautet ein viel strapaziertes Motto der Protagonisten nachhaltiger Entwicklung, die den regionalen und kommunalen Initiativen eine zentrale Rolle bei der Umsetzung nachhaltiger Entwicklung zuweisen. Das war ein Grund, warum sich das HGF-Verbundprojekt mit ihnen beschäftigte. Außerdem können solche Initiativen Laboratorien sein, in denen mit dem experimentiert wird, was theoretisch als Leitbild nachhaltiger Entwicklung konzipiert wird. Die Untersuchung der Praxis von Nachhaltigkeit als kritische Analyse der Wirklichkeit, gemessen an dem, was Nachhaltigkeit sein soll (oder könnte), aber auch als Anfrage an die „Theorie“ der 